\title{
Light emission from Er at the As-terminated Sil111) surface
}

\section{Citation}

Evans, P. G., and J. A. Golovchenko. 2000. Light Emission from Er at the As-Terminated Si(111) Surface. Applied Physics Letters 77, no. 14: 2165. doi:10.1063/1.1315335.

\section{Published Version}

doi:10.1063/1.1315335

\section{Permanent link}

http://nrs.harvard.edu/urn-3:HUL.InstRepos:29405823

\section{Terms of Use}

This article was downloaded from Harvard University's DASH repository, and is made available under the terms and conditions applicable to Other Posted Material, as set forth at http:// nrs.harvard.edu/urn-3:HUL.InstRepos:dash.current.terms-of-use\#LAA

\section{Share Your Story}

The Harvard community has made this article openly available.

Please share how this access benefits you. Submit a story.

Accessibility 


\title{
Light emission from $\mathrm{Er}$ at the As-terminated $\mathrm{Si}(111)$ surface
}

\author{
P. G. Evans and J. A. Golovchenko ${ }^{\text {a) }}$ \\ Division of Engineering and Applied Sciences, Harvard University, Cambridge, Massachusetts 02138
}

(Received 3 July 2000; accepted for publication 8 August 2000)

\begin{abstract}
Erbium atoms at an arsenic-terminated $\mathrm{Si}(111)$ surface can be made to emit light at the $1.55 \mu \mathrm{m}$ wavelength associated with an internal transition in the $\mathrm{Er}^{3+}$ ion. The As-terminated surface prepared under ultrahigh vacuum conditions has a surface recombination velocity of $50 \mathrm{~cm} \mathrm{~s}^{-1}$ and partially suppresses competing nonradiative recombination mechanisms. Following the deposition of Er, its characteristic light emission is observed only after oxygen reacts with the surface. The intensity of the light emitted by Er increases significantly upon cooling from 310 to $215 \mathrm{~K}$. No light emission was observed from Er atoms deposited on $7 \times 7$ or H-terminated surfaces. (C) 2000 American Institute of Physics. [S0003-6951(00)04140-1]
\end{abstract}

The use of Er as a light emitting impurity in Si has been motivated by potential device applications which take advantage of the fact that the energy of an internal transition in the $\mathrm{Er}^{3+}$ ion corresponds with the wavelength of minimum absorption of silica optical fibers. ${ }^{1}$ In bulk Si the excitation of Er occurs by the transfer of energy from excess electrons and holes to the Er ion. Certain aspects of the atomic scale environment of optically active Er atoms have been determined by extended $\mathrm{x}$-ray absorption fine structure measurements, ${ }^{2,3}$ the study of the crystal-field splitting on photoluminescence spectra, ${ }^{4}$ and by modifying the chemical environment of the Er with ion implantation of impurities. ${ }^{5}$ The conclusion of these studies is that Er atoms must be coordinated with impurities, such as oxygen, to participate efficiently in the light emission process.

A more comprehensive understanding of the local atomic and electronic structure of the optically active Er and its environment will contribute to a deeper understanding of light emission processes for silicon based devices. Towards this end, we have discovered that Er ions at the Asterminated $\mathrm{Si}(111)$ surface emit $1.55 \mu \mathrm{m}$ light in ways that are related to the behavior of Er in the bulk: optical activity is induced by oxidation of the Er doped surface. This observation makes Er and other optically active dopants susceptible to study by photoemission and scanning probe tools.

These experiments were carried out in an ultrahigh vacuum (UHV) chamber equipped with sources of As and Er. The sample was held so that both faces could be studied by low energy electron diffraction (LEED) and Auger electron spectroscopy. Minority carrier lifetime measurements were performed in UHV using an eddy-current based contactless photoconductivity decay method. ${ }^{6}$ Excess carriers were excited for the lifetime measurement using up to 10 $\mathrm{mW}$ of $905 \mathrm{~nm}$ light. For optical spectroscopy, two laser diodes, with wavelengths centered near 800 and $900 \mathrm{~nm}$, respectively, could be interchanged as sources of the $0.4 \mathrm{~W}$ pump beam. A spot $0.2 \times 0.4 \mathrm{~cm}^{2}$ was illuminated. The current to the laser diode was modulated to produce $50 \%$ duty cycle square pulses at $100 \mathrm{~Hz}$ for use in synchronous detection. Light emitted by the sample was collected by a lens,

${ }^{\text {a)} E l e c t r o n i c ~ m a i l: ~ g o l o v c h e n k o @ p h y s i c s . h a r v a r d . e d u ~}$ dispersed by a monochromator, and sent to a liquid nitrogen cooled Ge detector. ${ }^{7}$

The $1 \mathrm{~cm} \times 2 \mathrm{~cm}$ samples were cleaved from $500 \mu \mathrm{m}$ thick, (111) oriented, $>1000 \Omega \mathrm{cm}$ resistivity, $p$-type wafers. Measurements performed with the sample immersed in concentrated HF indicated a lower limit of $700 \mu$ s for the bulk minority carrier lifetime. ${ }^{8}$ Following chemical oxidation by the Shiraki process, ${ }^{9}$ the samples were loaded into UHV. Resistive heating to $875^{\circ} \mathrm{C}$ to evaporate the oxide layer produced the $7 \times 7$ LEED pattern on both sides of the sample. Bulk defects generated during heating resulted in a decrease in the bulk lifetime to $400 \mu \mathrm{s}$, as observed by measurements in HF after removing the sample from UHV.

The arsenic terminating layer was deposited by cooling the sample from 875 to $350^{\circ} \mathrm{C}$ in a flux of As vapor from an effusion cell that was set to fill the chamber to a pressure of $10^{-5}$ Torr. Both sides of the sample then exhibited a sharp $1 \times 1$ LEED pattern that has been previously associated with As atoms residing near substitutional sites. ${ }^{10}$ The As coverage was $0.96 \pm 0.05 \mathrm{ML}\left(1 \mathrm{ML}=7.83 \times 10^{14}\right.$ atoms cm$\left.^{-2}\right)$. Surface coverages of As and Er were measured using Rutherford backscattering spectrometry after removing the sample from UHV. Before termination with As, the minority carrier lifetime with the $7 \times 7$ surface was less than $15 \mu$, the minimum decay time measurable with our apparatus. A short lifetime is consistent with the high surface recombination velocity for the $7 \times 7$ surface reported in previous measurements. ${ }^{11}$ With As-terminated surfaces, the minority carrier lifetime reached $255 \mu \mathrm{s}$. The corresponding surface recombination velocity was $50 \mathrm{~cm} \mathrm{~s}^{-1}$, which is similar to previous results. ${ }^{12}$ With the more intense pump beam used for light emission measurements, the surface recombination velocity was $500 \mathrm{~cm} \mathrm{~s}^{-1}$. An Auger peak due to $\mathrm{C}$ was observed following As termination, with a Si LVV to C KLL ratio of 50:1.

Submonolayer amounts of Er were deposited on the surface from an Er foil spot welded to a Ta foil which was resistively heated to $900^{\circ} \mathrm{C}$. During Er deposition, the pressure rose briefly to $3 \times 10^{-10}$ Torr. The addition of Er atoms to the As-terminated $\mathrm{Si}(111)$ surface produced an immediate drop in the intensity of band-gap light emission observed during luminescence measurements, due to a drop in the mi- 


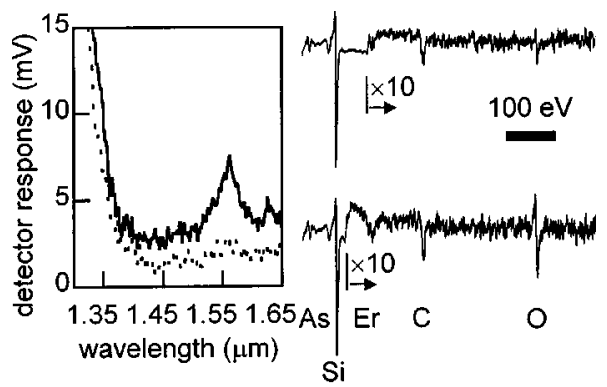

(a)

(b)

FIG. 1. (a) Photoluminescence spectra $1 \mathrm{~h}$ (dashed) and $15 \mathrm{~h}$ (solid) after depositing $0.2 \mathrm{ML}$ Er. The increase in intensity at short wavelengths indicates the onset of band-gap luminescence. (b) Auger electron spectra acquired in the $d N / d E$ mode $0.4 \mathrm{~h}$ (top) and $26.5 \mathrm{~h}$ (bottom) after the $\mathrm{Er}$ deposition. Peaks due to $\mathrm{As}, \mathrm{Si}, \mathrm{Er}, \mathrm{C}$, and $\mathrm{O}$ are labeled.

nority carrier lifetime. Following the deposition of $0.2 \mathrm{ML}$ Er, the intensity fell by a factor of 5 . In the first few hours after depositing Er, there was no peak in the photoluminescence spectrum corresponding to light emitted by Er.

Within $15 \mathrm{~h}$ following the deposition of Er, a peak at $1.55 \mu \mathrm{m}$ appeared in the photoluminescence spectrum. Figure 1(a) shows photoluminescence spectra taken 1 and $15 \mathrm{~h}$ after depositing 0.2 ML Er. Auger spectra in Fig. 1(b), taken 0.4 and $26.2 \mathrm{~h}$ after the deposition, show an increase over time in the oxygen KLL Auger peak at $505 \mathrm{eV}$. Following the initial increase of the oxygen peak, there was no additional oxidation of the surface in subsequent days. The appearance of oxygen was accompanied by a return of the band-gap light intensity to approximately half its value before the Er deposition. The limited oxidation of the surface following the deposition of Er suggests that the deposited Er atoms are oxidized by the residual gas. The base pressure in the chamber was $1 \times 10^{-10}$ Torr. The emission of light at $1.55 \mu \mathrm{m}$ only after the oxidation of $\mathrm{Er}$ at the surface is consistent with bulk studies in which efficient light emission requires the coordination of Er with impurities. ${ }^{2} \mathrm{~A}$ similar oxidation of submonolayer Er films deposited on the $\mathrm{Si}(111)$ $7 \times 7$ surface has been previously observed in $\mathrm{x}$-ray studies. $^{13}$

By varying the wavelength of the pump beam while measuring the intensity of the luminescence at $1.55 \mu \mathrm{m}$, a distinction was made between direct absorption of the pump beam by Er compounds and absorption by the $\mathrm{Si}$ substrate followed by transfer of energy to Er at the surface. The intensity of the $1.55 \mu \mathrm{m}$ fluorescence of Er on As-terminated $\mathrm{Si}$ and of $\mathrm{Er}_{2} \mathrm{O}_{3}$ powder are plotted in Fig. 2 as function of pump wavelength, which was tuned by varying the temperature of the laser diode in the range $0-30{ }^{\circ} \mathrm{C}$. At each point, the intensity is normalized using the incident optical power. The fluorescence of $\mathrm{Er}_{2} \mathrm{O}_{3}$ powder shows a strong dependence on pump wavelength due to direct resonance excitation of Er. The intensity of the fluorescence from $\mathrm{Er}_{2} \mathrm{O}_{3}$ pumped near $800 \mathrm{~nm}$ is a factor of 400 greater than when pumped near $900 \mathrm{~nm}$. Comparing the pump wavelengths with the level structure of $\mathrm{Er}$ in $\mathrm{Er}_{2} \mathrm{O}_{3}$ suggests that for the $\mathrm{Er}_{2} \mathrm{O}_{3}$ sample the excitation of the Er was strongest with the pump laser wavelength tuned to the ${ }^{4} I_{15 / 2}-{ }^{4} I_{9 / 2}$ transition near $800 \mathrm{~nm} .{ }^{14}$ A similar variation of the absorption cross section with wavelength is found for Er doped silica fibers. ${ }^{15}$ In contrast, the fluorescence of the Er atoms on the As- lar or superior results from Er at solid surfaces.
Downloaded 14 Dec 2005 to 128.103.60.225. Redistribution subject to AlP license or copyright, see http://apl.aip.org/apl/cor

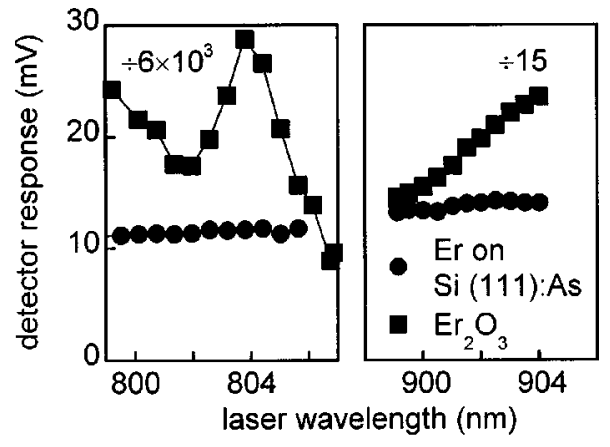

(a)

(b)

FIG. 2. Fluorescence of $\mathrm{Er}_{2} \mathrm{O}_{3}$ (squares) and $\mathrm{Er}$ on As-terminated $\mathrm{Si}(111)$ (circles) vs pump laser wavelength: (a) Near $800 \mathrm{~nm}$, (b) near $900 \mathrm{~nm}$. In each plot, the signal from $\mathrm{Er}_{2} \mathrm{O}_{3}$ has been attenuated by the indicated factor.

terminated surface was nearly independent of pump wavelength indicating that band-gap absorption by the Si substrate was responsible for the ultimate excitation of the Er atoms at the surface.

The surface recombination of electrons and holes resulting in light emission from Er competes with nonradiative recombination at surface defects. In analogy to the situation in which competing bulk processes are each characterized by a lifetime, the radiative and nonradiative surface recombination can each be assigned a surface recombination velocity. Using the absolute calibration of the detector system $(1 \mathrm{mV}$ peak signal $=5 \times 10^{8}$ photons $\mathrm{cm}^{-2} \mathrm{~s}^{-1}$ from the sample), an estimate of the relative magnitudes of the surface recombination velocities can be made.

An upper limit on the flux of excess carriers to the surface can be obtained by assuming that all of the electron-hole pairs created by absorption of the pump laser recombine at the surface. Assuming that each photon absorbed from the pump beam creates one pair of excess carriers, the flux of excess electrons to the surface is $\Phi_{e}=2 \times 10^{19} \mathrm{~cm}^{-2} \mathrm{~s}^{-1}$. In terms of the total surface recombination velocity $\nu_{s}$, the concentration of electrons at the surface $n_{s}$ is

$$
n_{s}=\frac{\Phi_{e}}{\nu_{s}} .
$$

The total surface recombination velocity, which is due almost entirely to nonradiative processes, is $\nu_{s}=500 \mathrm{~cm} \mathrm{~s}^{-1}$ when the sample is illuminated by the pump laser beam. The rate of radiative surface recombination is

$$
\Phi_{p}=\nu_{s}^{r} n_{s} .
$$

From Eqs. (1) and (2) we find that the ratio of the radiative surface recombination velocity to the total surface recombination velocity for our best sample, with $0.1 \mathrm{ML} \mathrm{Er}$, is $10^{-8}$ at room temperature. Because the surface recombination velocity depends both on cross sections for electron and hole capture by defects and on the potential difference between the surface and the bulk of the sample, ${ }^{16}$ it is not meaningful to use the present value for $\nu_{s}^{r}$ to determine a cross section for the light emission process. Room temperature quantum efficiencies of $10^{-4}$ for photoluminescence of $\mathrm{Er}$ in Si have been reported. ${ }^{17}$ It will be an interesting challenge to identify and optimize the surface conditions necessary to obtain similar or superior results from Er at solid surfaces. 


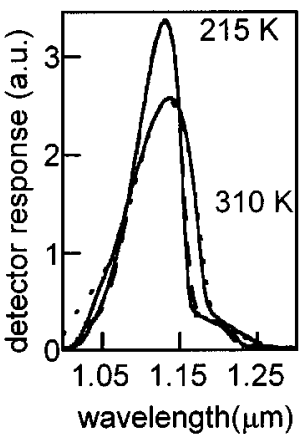

(a)

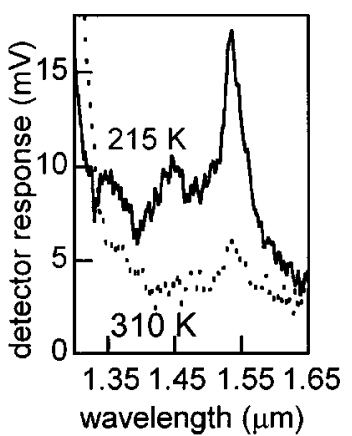

(b)
FIG. 3. (a) Band-gap light emission with and without cooling (solid lines). Fits to the spectra (dashed lines) give sample temperatures of $310 \mathrm{~K}$ without cooling and $215 \mathrm{~K}$ with cooling. (b) Increase in light emission from $\mathrm{Er}$ atoms at As-terminated Si surface upon cooling from $310 \mathrm{~K}$ (dashed line) to $215 \mathrm{~K}$ (solid line).

Cooling the sample through a $\mathrm{Cu}$ braid connected to a liquid nitrogen reservoir allowed the temperature dependence of the light emission from the Er atoms at the surface to be studied at temperatures from 215 to $310 \mathrm{~K}$. The temperature dependence of the band-gap luminescence was used to measure the sample temperature by comparing the observed spectrum with one predicted using the van Roosbroeck-Schockley relation. ${ }^{18}$ Agreement between theory and experiment is extremely good, as demonstrated in Fig. 3(a). Figure 3(b) shows the increase in the intensity of the peak at $1.55 \mu \mathrm{m}$ upon cooling from 310 to $215 \mathrm{~K}$, for a sample with 0.2 ML Er. A similar increase in intensity upon cooling observed for $\mathrm{Er}$ in bulk Si was attributed to a reduction in the thermally activated deexcitation of the Er ion. ${ }^{19} \mathrm{In}$ those studies, the intensity of the Er luminescence above 100 $\mathrm{K}$ was proportional to $\exp (E / k T)$, where $E \approx 0.15 \mathrm{eV}$ was the effective activation energy for the return of carriers from $\mathrm{Er}$ related traps to levels in the Si bands. ${ }^{19}$ For our measurements, the increase in intensity upon cooling by a factor of 3.7 observed in Fig. 3(b), after subtracting the background, gives $E \approx 0.08 \mathrm{eV}$. The cause of the difference between the present result and the previously reported value of $E$ may include effects of changes in the total surface recombination velocity with temperature, and/or a difference in the energy of the Er-related defect level through which an Er ion is excited.

No light emission was observed from $\mathrm{Er}$ on H-terminated surfaces loaded into UHV after wet etching. ${ }^{20}$ Although H-terminated samples exhibited a low surface recombination velocity before the deposition of Er, there was no recovery of the lifetime in the hours following the Er deposition in contrast to As-terminated Si. No light emission from Er was detected for Er deposited on $7 \times 7$ or chemically oxidized surfaces, which can be attributed in part to the high surface recombination velocities associated with these surface preparations. Light emission from Er atoms on the As- terminated $\mathrm{Si}(111)$ surface also ceased upon removing the sample from UHV.

Future experiments taking advantage of the tools of surface science will further the study of the mechanisms by which energy is transferred from excited carriers in $\mathrm{Si}$ to $\mathrm{Er}$ atoms at the surface. The issues to be resolved for a complete understanding of surface light emission include the effects of surface potential, the origins of nonradiative surface recombination, and the detailed environment of the Er atoms. It is our hope that by optimizing the conditions for Er light emission at surfaces these regions can ultimately be incorporated in bulk devices via epitaxial growth techniques. ${ }^{21}$

The authors acknowledge the contributions of S. A. McDonald and support from the Rowland Institute for Science and the Harvard University Materials Research Science and Engineering Center.

${ }^{1}$ A. Polman, J. Appl. Phys. 82, 1 (1997).

${ }^{2}$ D. L. Adler, D. C. Jacobson, D. J. Eaglesham, M. A. Marcus, J. L. Benton, J. M. Poate, and P. H. Citrin, Appl. Phys. Lett. 61, 2181 (1992).

${ }^{3}$ A. Terrasi, G. Franzò, S. Coffa, F. Priolo, F. D'Acapito, and S. Mobilio, Appl. Phys. Lett. 70, 1712 (1997).

${ }^{4}$ S. Lanzerstorfer, L. Palmetshofer, W. Jantsch, and J. Stimmer, Appl. Phys. Lett. 72, 809 (1998)

${ }^{5}$ J. Michel, J. L. Benton, R. F. Ferrante, D. C. Jacobson, D. J. Eaglesham, E. A. Fitzgerald, Y.-H. Xie, J. M. Poate, and L. C. Kimerling, J. Appl. Phys. 70, 2672 (1991).

${ }^{6}$ G. L. Miller, D. A. H. Robinson, and S. D. Ferris, Proc. Electrochem. Soc. 78-3, 1 (1978).

${ }^{7}$ North Coast Scientific, Santa Rosa, CA, Model EO-817L.

${ }^{8}$ E. Yablonovitch, D. L. Allara, C. C. Chang, T. Gmitter, and T. B. Bright, Phys. Rev. Lett. 57, 249 (1986).

${ }^{9}$ A. Ishizaka and Y. Shiraki, J. Electrochem. Soc. 133, 666 (1986).

${ }^{10}$ J. R. Patel, J. A. Golovchenko, P. E. Freeland, and H.-J. Gossmann, Phys. Rev. B 36, 7715 (1987); M. A. Olmstead, R. D. Bringans, R. I. G. Uhrberg, and R. Z. Bachrach, ibid. 34, 6041 (1986).

${ }^{11}$ J. W. P. Hsu, C. C. Bahr, A. vom Felde, S. W. Downey, G. S. Higashi, and M. J. Cardillo, J. Vac. Sci. Technol. A 10, 985 (1992).

${ }^{12}$ J. W. P. Hsu, C. C. Bahr, A. vom Felde, S. W. Downey, G. S. Higashi, and M. J. Cardillo, J. Appl. Phys. 71, 4983 (1992).

${ }^{13}$ P. Castrucci, F. Yubero, F. C. Vicentin, J. Vogel, and M. Sacchi, Phys. Rev. B 52, 14035 (1995).

${ }^{14}$ J. B. Gruber, J. R. Henderson, M. Muramoto, R. Rajnak, and J. G. Conway, J. Chem. Phys. 45, 477 (1966).

${ }^{15}$ W. J. Miniscalco, J. Lightwave Technol. 9, 234 (1991); W. J. Miniscalco (private communication).

${ }^{16}$ E. Yablonovitch, R. M. Swanson, W. D. Eades, and B. R. Weinberger, Appl. Phys. Lett. 48, 245 (1985).

${ }^{17}$ F. Priolo, G. Franzò, S. Coffa, and A. Carnera, Phys. Rev. B 57, 4443 (1998).

${ }^{18}$ W. van Roosbroeck and W. Shockley, Phys. Rev. 94, 1558 (1954); J. I. Pankove, Optical Processes in Semiconductors (Dover, New York, 1975), pp. $108-111$

${ }^{19}$ F. Priolo, G. Franzò, A. Polman, S. Libertino, R. Barklie, and D. Carey, J. Appl. Phys. 78, 3874 (1995); P. G. Kik, M. J. A. de Dood, K. Kikoin, and A. Polman, Appl. Phys. Lett. 70, 1721 (1997).

${ }^{20}$ S. Bouzidi, F. Coletti, J. M. Debever, P. A. Thiry, P. Dumas, and Y. J. Chabal, Phys. Rev. B 45, 1187 (1992).

${ }^{21}$ H.-J. Gossmann, E. F. Schubert, D. J. Eaglesham, and M. Cerullo, Appl. Phys. Lett. 57, 2440 (1990); O. D. Dubon, P. G. Evans, M. F. Chisholm, D. A. Muller, M. J. Aziz, F. Spaepen, and J. A. Golovchenko (unpublished). 